\title{
A relação cognição e linguagem e o papel da consciência
}

Marilene Tavares Cortez $z^{1}$

Universidade do Estado de Minas Gerais (UEMG/INESP/Divinópolis)

Este texto discute como a concepção de aprendizagem depende diretamente da ontologia que emerge de teorias que buscam compreender a cognição humana. A análise de alguns aspectos teórico-epistemológicos desenvolvidos pela ciência moderna ressaltou que a eliminação do conceito de consciência desta investigação foi uma opção ideológica. Procurei mostrar a necessidade de uma nova metodologia, a partir da vinculação da psicologia cognitiva e da lingüística cognitiva, para investigar a cognição humana. Espera-se que tal metodologia leve em consideração a consciência, uma vez que pesquisas recentes sobre este tema buscam, cada vez mais, ampliar compreensão desse fenômeno.

This text discusses how the conception of learning is directly dependent on the ontology which emerges from theories which try to understand human cognition. The analysis of certain theoretical-epistemological aspects developed by modern science highlighted the fact that the elimination of the concept of consciousness was an ideological option. I tried to show the necessity of a new methodology, departing from the linking of Cognitive Psychology and Cognitive Linguistics, to investigate human cognition. It is desirable that such methodology takes into consideration consciousness, since recent researches on the theme have been increasingly devoted to the understanding of this phenomenon.

\footnotetext{
"Não seria possível formular as leis da mecânica quântica de modo consistente sem referência à nossa consciência. O estudo do mundo nos devolve ao estudo de nossa própria consciência".
}

(WIGNER apud Teixeira, 2000, p. 87) ${ }^{2}$

\footnotetext{
1 Professora de Fundamentos Históricos e Epistemológicos da Psicologia, Psicologia Cognitiva e Terapia Cognitiva da UEMG/Divinópolis. Doutoranda em Lingüística Aplicada, PosLin/UFMG.

${ }^{2}$ WIGNER, E. Remarks on the mind-body question. In: GOOD, I.J. The scientist speculates: An anthology of partly baked ideas. Londres: Heinemann, 1962.
} 


\section{Introdução}

O tema proposto pela Revista Brasileira de Lingüistica Aplicada, "Cognição e aprendizagem de linguas", remete-nos, imediatamente, a um espaço de interseção da lingüística e da psicologia, o da busca da compreensão da relação entre cognição e linguagem e de como se dá a aprendizagem. Sendo assim, um dos principais objetivos deste texto é fazer algumas reflexões teóricas acerca dessa relação, uma vez que um dos desdobramentos mais importantes quando se investiga a relação cognição e linguagem, em uma perspectiva históricoepistemológica, é que se estabelece, explícita ou implicitamente, uma ontologia humana, conforme buscaremos mostrar. Uma definição de ser humano afeta diretamente a maneira como entendemos o que é ou como supomos ser a aprendizagem. De fato, basta pensarmos nos modelos propostos pela psicologia comportamental e pela psicologia da gestalt para a aprendizagem e compreendemos, de imediato, que se trata de ontologias absolutamente distintas. Na primeira abordagem, o ser humano é visto como tabula rasa, homem-máquina, na qual tudo se poderia inscrever através de condicionamentos. Assim, a aprendizagem depende da habilidade de quem ensina em manejar adequadamente os estímulos dados aos aprendizes (PENNA, 2001, p. 47-50, 57-63; 1980, p. 61-83).

Com a psicologia da gestalt inaugura-se, na psicologia, a investigação dos processos cognitivos envolvidos na aprendizagem, tal qual entendemos tais processos atualmente. As pesquisas gestaltistas sobre a aprendizagem e solução de problemas ${ }^{3}$ significaram um extremo refinamento sobre o que se entendia por cognição. Os gestaltistas investigaram, inclusive, a relação da consciência com a aprendizagem (Cf. PENNA, 1980, p. 194-198; 2001, p. 65-68). Através da psicologia da gestalt, o ser humano é visto como um ser ativo e criativo, que aprende através da introvisão (insights), isto é, ocorre uma reestruturação perceptiva. Tal reestruturação envolve o fenômeno da

\footnotetext{
3 Vale lembrar o trabalho seminal desenvolvido por Köhler no Tenerife, em Estação de antropóides nas ilhas Canárias, de 1913-1920, a partir do qual os gestaltistas desenvolvem o conceito de reestruturação perceptiva ao investigarem como se dá a aprendizagem.
} 
consciência, o qual faz com que a aprendizagem se dê de uma forma integradora, ou seja, há o envolvimento de diferentes planos cognitivos para que essa ocorra. Para os gestaltistas, portanto, aprender é promover alterações em uma configuração. Destarte, esses dois modelos sobre o processo de aprendizagem, oriundos de diferentes correntes dentro da psicologia, são vetores, também, de diferentes ontologias. Veremos ao longo do texto, portanto, que o desenvolvimento da ciência moderna acarretou uma estreita vinculação entre a epistemologia e a ontologia. Essa constatação reforça a necessidade de se fazer uma reflexão epistemológica sobre a forma como o conceito de cognição foi desenvolvido ao longo de toda a modernidade, uma vez que há uma estreita relação entre a epistemologia e a ontologia.

Para desenvolvermos uma reflexão em uma perspectiva crítica sobre a relação cognição e aprendizado, é necessário que não percamos de vista que as pesquisas sobre a cognição humana são transdisciplinares (Cf. DUPUY, 1996; GARDNER, 1996; TEIXEIRA, 1998; VARELA et alii, 2003). Assim, é necessário ter clareza sobre os pressupostos teóricoepistemológicos dos modelos adotados, para que não haja uma incompatibilidade entre as teorias e entre as metodologias as quais foram vinculadas. Compreender como as ciências cognitivas se apropriaram, ou, mais ainda, se constituíram, desde 1956, a partir da discussão sobre a relação entre cognição e linguagem, discussão que já vinha sendo feita na psicologia e lingüística, ${ }^{4}$ irá nos ajudar a entender como nos dias atuais essa discussão "retorna" aos campos da psicologia cognitiva e da lingüística cognitiva (LC, doravante), através das ciências cognitivas.

Acredito que pensar como essa relação entre a cognição e a linguagem tem se delineado desde a fundação da psicologia em 1879, e buscar compreender como a lingüística tem se posicionado diante desse tema pode ajudar na construção de um modelo acerca dos processos cognitivos e da consciência que escape à metáfora computacional, inaugurada com o movimento ciberneticista (Cf.

${ }^{4}$ Como se sabe, a Psicolingüistica foi formalizada em 1954 e foi uma tentativa de síntese a partir da psicologia do aprendizado, da teoria da informação e da lingüística (Cf. MELO, 1999, p. 17). 
DUPUY, 1996) e que ainda hoje guia as principais pesquisas na psicologia cognitiva através da primazia da investigação do processamento de informação (Cf. ANDERSON, 2004, p. 6).

A cibernética ajudou a firmar a ontologia humana do autômato, isto é, o ser humano passou a ser visto como uma máquina, um autômato, desde os primórdios da fundação da ciência moderna, a partir das proposições cartesianas (Cf. TEIXEIRA, 2003, p. 36-40; PENNA, 2003, p. 14-15, 28-32). Tal confirmação só foi possível em função da maneira como os ciberneticistas articularam a relação entre cognição e linguagem, discussão que também permeia o texto cartesiano. Assim, para conseguirmos desenvolver uma crítica acerca da construção desse modelo para o ser humano, como um autômato, é necessário compreender alguns princípios epistemológicos fundacionais da ciência moderna, procurando refletir, inclusive, sobre o porquê da elisão do conceito de consciência feita pelos ciberneticistas.

Reflexões teóricas tornam-se imprescindíveis para que as teorias científicas descrevam o fenômeno por elas investigado de forma mais eficaz. É dentro desta óptica que podemos compreender a proposição de Einstein segunda a qual "é a teoria que determina o que podemos observar" (apud SCHULTZ e SCHULTZ, 1992, p. 28). Podemos ainda encontrar em Vigotski, não só o interesse em investigar a relação pensamento, linguagem e consciência, como também uma preocupação com as reflexões teóricas: "As discussões teóricas e críticas são uma precondição necessária e um complemento da parte experimental do estudo, constituindo uma grande parte de nosso livro" (Vigotski, 2003, p. XIX) $)^{5}$ (grifo da autora).

Alan Schoenfeld procura demonstrar porque as práticas educacionais devem ser guiadas pelas teorias (Cf. SCHOENFELD, 1999, p. 13-27). Esse autor busca compreender como o indivíduo aprende, levando em consideração o seu contexto social, por isso o seu trabalho é lido como paralelo ao de Vigotski por Frawley (Cf. FRAWLEY, 2000, p. 158-165), contudo, a maior contribuição de Schoenfeld foi fazer

5 É no livro Pensamento e Linguagem que Vigotski discute longamente a relação entre o pensamento, a linguagem e a consciência. Livro publicado postumamente em 1934. 
avançar a discussão de como se estabelece a relação entre indivíduo, o social e a consciência do aluno no momento da aprendizagem.

(Schoenfeld) tem argumentado que as explicações de grande parte do desempenho dos alunos requer informações "além de puramente cognitivas" (SCHOENFELD, 1983), além das manipulações internas do código da mente. Crenças, intuições, autoconsciência (self-awareness), contexto da sala de aula, autopercepção e autocontrole, tudo isso tem sua ligação com a aprendizagem e o ensino da matemática. (FRAWLEY, 2000, p. 158).

Pode-se notar, a partir desse excerto, que Schoenfeld, dentre outros pensadores, desde a década de 1980 voltou a pensar a relação entre aprendizado e consciência, como já faziam os gestaltistas, por exemplo, desde o início do século XX. Assim, conseguir construir um modelo teórico sobre aprendizagem que nos permita escapar da metáfora computacional, bem como da dicotomia social ${ }^{6}$ versus individuo é um desafio premente. Tomasello (2003, p. 225-228) explicita a dificuldade dos modelos científicos em desenvolver uma teoria sobre "como as crianças aprendem", de forma que conciliem os aspectos universais e particulares envolvidos na aprendizagem. Schoenfeld dá uma contribuição preciosa para essa questão ao ampliar

${ }^{6}$ Não há qualquer dúvida sobre o quanto trabalhos como os de Vigotski e Bakhtin foram seminais para se pensar a relação sociedade e indivíduo, por exemplo. Contudo, mesmo a literatura da psicologia cultural, que parte da premissa da primazia do social sobre o indivíduo, reconbece que após mais de cinqüenta anos de pesquisa sobre tal primazia ainda não se consegue ter clareza sobre a influência de alguns aspectos sociais, como a linguagem, sobre os processos cognitivos individuais. É o que pondera Olson em $A$ escrita e a mente, no livro compilado por Wertsch et ali em Estudos socioculturais da mente (Cf. OLSON, 1998, p. 89-111). Acredito que estes mais de cinqüenta anos de pesquisas apontam para o fato de que não podemos mais considerar "a consciência individual (como) um fato sócio-ideológico [...] a consciência só se torna consciência quando se impregna de conteúdo ideológico", exclusivamente, como queria Bakhtin em seu texto Marxismo e filosofia da linguagem (Cf. BAKHTIN, 1986, p. 34-35), ou alojar a consciência no social, exclusivamente, como também propôs Vigotski (2003). É necessário pensar aspectos ligados à subjetividade e consciência e procurar diferenciar consciência de cognição, confusão mantida por Damásio (2000), isto é, pela neurobiologia cognitiva. 
a compreensão sobre como se dá a relação entre contexto e o indivíduo, mostrando que é necessário levar em consideração os conceitos de self e consciência para que se entenda como o indivíduo aprende. Em outras palavras, é necessário que o indivíduo se "perceba" para que possa aprender, ou como colocou Schoenfeld, a autoconsciência é necessária para que se dê a aprendizagem. Portanto, trabalhos como os de Schoenfeld tornam-se uma referência importante porque, ao partir da premissa de que há uma relação estreita entre cultura e indivíduo, procuram investigar o que ocorre internamente no indivíduo, não subsumindo o indivíduo na cultura, como fizeram Vigotski, Bakhtin e Whorf,7 por exemplo.

Destacar o trabalho de Schoenfeld é importante para ajudar a reforçar a idéia de que as discussões teóricas têm papel determinante para a alteração da prática. Assim, com o retorno ${ }^{8}$ da discussão sobre o conceito de consciência a partir dos anos de 1980 nas ciências cognitivas, podem-se acompanhar mudanças no próprio entendimento de como se processa a aprendizagem, conforme pontua Schoenfeld.

\footnotetext{
7 Os trabalhos de Rosch, desenvolvidos a partir dos anos de 1970, nos quais investigou as relações entre cognição, linguagem e cultura, em função da percepção das cores pelos indivíduos, são tomados como uma crítica contundente à supremacia dada aos estudos culturais (Cf. GARDNER,1996, p. 363-369).

${ }^{6}$ O retorno da consciência, expressão usada por Frawley (2000, p. 120-166) nas discussões sobre mente, cérebro, cognição e linguagem, ocorreu a partir do final da década de 1980 (Cf. TEIXEIRA, 2003, p. 153-182). É importante destacar o que Searle defende em seu livro O mistério da consciência acerca do "ressurgimento" da discussão sobre o conceito de consciência. "Esta época é, ao mesmo tempo, a mais excitante e a mais frustrante [...] Excitante porque o tema da consciência voltou a ser respeitado - de fato, quase que considerado central - como matéria de investigação da filosofia, da psicologia, ciências cognitivas e até da neurociência" (SEARLE, 1998, p. 23). Vale lembrar, ainda, a trilogia escrita por Damásio, na perspectiva da neurobiologia cognitiva, através da qual este autor busca compreender a relação mente-corpo, questão fundacional da psicologia, e que tem a investigação da consciência como um dos aspectos axiais: O mistério da consciência: do corpo e das emoçôes ao conbecimento de si (2000), O erro de Descartes: emoção, razão e cérebro humano (2001), Em busca de Espinosa: prazer e dor na ciência dos sentimentos (2004).
} 
Dessa maneira, é necessário que formulemos explicitamente algumas questões, tais como: qual o papel da consciência no processo de aprendizagem?; qual a relação da consciência com os processos cognitivos de maneira geral, portanto, com a linguagem, e como aprendemos, afinal?; a consciência pode ser compreendida como apenas mais um dos processos cognitivos?

Assim, dentro deste objetivo mais amplo do texto de delinear alguns aspectos teóricos da discussão que se faz há mais de cem anos na psicologia sobre a relação linguagem e cognição, há quase cem anos dentro da lingüística e há sessenta anos nas ciências cognitivas, procuro endereçar essa discussão para a lingüística cognitiva, uma vez que a LC rompeu com a vertente hegemônica da lingüística gerativista, devido à adesão desta última ao modelo computacional da linguagem, e procura, portanto, desenvolver uma nova teoria sobre a relação cognição e linguagem (JANDA, 2000; SINHA, 2001). Destarte, a LC parte da premissa de que a linguagem é apenas um dos vários processos cognitivos humanos e, diferentemente da perspectiva gerativista, não acredita que haja um módulo cognitivo especial para que a linguagem humana seja desenvolvida. Contudo, a pergunta que colocamos para a LC é se há uma compreensão teórica suficiente, ou clareza epistemológica em seu corpo teórico, para encampar essa discussão acerca do "retorno" do conceito de consciência, uma vez que a consciência encontra-se completamente envolvida na produção de significado na linguagem e, para a LC, "a questão mais fundamental numa teoria lingüística é a natureza do significado e como lidar com ele" (LANGACKER, 1987, p. 5). Dessa forma, é fundamental para a LC compreender como o conceito de consciência é compreendido pela psicologia cognitiva ${ }^{9}$ e por outros segmentos das ciências cognitivas. Assim, o que procuro mostrar no texto é que é necessário ter clareza teórico-epistemológica sobre a teoria que se adota, ou as alianças

\footnotetext{
${ }^{9}$ A psicologia cognitiva que se afilia à tradição gestaltista e que tem, portanto, o conceito de consciência como objeto de estudo estabelece que o conceito de consciência é "fator excepcionalmente relevante em sua função de organização e coordenação do comportamento e em sua função de doação de significado aos eventos que ocorrem no mundo" (PENNA, 1999, p. 9) (grifo da autora). Proposição que não ocorre em outros veios das ciências cognitivas, como na neurociência.
} 
teóricas buscadas, pois cada modelo teórico tem implicações e desdobramentos que precisam ser compreendidos e assumidos. ${ }^{10}$

Como última observação antes de avançar no texto, gostaria de destacar que, assim como na psicologia há uma variedade expressiva de matizes teóricos, o mesmo ocorre na lingüística. Sendo assim, as minhas referências teóricas dentro de cada um desses campos são as da psicologia cognitiva e da LC.

\section{Uma questão histórico-epistemológica}

Através do delineamento de alguns aspectos históricoepistemológicos envolvidos na discussão sobre a relação cognição e linguagem, buscaremos compreender como o conceito de consciência foi abordado por alguns dos diversos campos do saber que se interessam por investigar essa relação, especialmente a psicologia e as ciências cognitivas.

Esta breve investigação histórica acerca da relação entre cognição e linguagem nos leva a refletir sobre o significado do termo retorno da consciência, como escreveu Frawley (2000). Essa expressão somente ganha relevância se nos ativermos ao veio hegemônico da ciência e especialmente das ciências cognitivas, proposição que buscaremos desenvolver ao longo do texto. Nessa medida podemos (re)lembrar que as ciências cognitivas passaram as últimas décadas estabelecendo modelos sobre cognição e linguagem e, portanto, também sobre a aprendizagem, sem levar em consideração o conceito de consciência. Há apenas duas décadas, a filosofia da mente "redescobriu a consciência" (Cf. TEIXEIRA, 2003, P. 153-182; FRAWLEY, 2000; SEARLE, 1998) e, assim, passamos a ler formulações tais como:

\footnotetext{
${ }^{10}$ Julgo importante ressaltar tal questão, já que a LC ainda se encontra em um momento de constituição de seu referencial teórico e conceitual. A LC nasceu fortemente ancorada nos estudos de categorização, oriundos das investigações de Rosch a partir da psicologia cognitiva e da antropologia, na década de 1970 (Cf. JANDA, 2000; GARDNER, 1996, p. 363-369), o que acarreta certos desdobramentos teórico-metodológicos e ontológicos. O estabelecimento de outras alianças teóricas requer uma investigação sobre a compatibilidade das teorias que se associam. Por exemplo, Collier (1998), ao analisar a compatibilidade entre a LC e o conexionismo, conclui que tal associação é inadequada, pois tais teorias partem de premissas distintas.
} 
Flanagan (1998) enfatiza que uma teoria da cognição que não leve em conta o papel que a consciência desempenha em nossa vida mental será necessariamente incompleta. O papel da experiência consciente na cognição deve ser o ponto de partida de uma teoria da consciência. (TEIXEIRA, 2003, p. 157).

A consciência está de volta. Um sinal claro de seu retorno impetuoso é que ela voltou com um grupo improvável de defensores. Os filósofos da mente declarados com tendências fortemente computacionais, como Dennett (1991) e Flanagan (1992), abraçaram a idéia de maneira reformulada, mas o mesmo foi feito por filósofos da mente declarados que, às vezes, apresentam um traço anticomputacional, como Searle (1992). Os cognitivistas com tendências clínicas e sociais, entre os quais Neisser (1992) e Baars (1988), argumentaram, o que não é surpresa alguma, a favor da consciência como uma idéia fundamental. Mas o mesmo foi feito por aqueles sem interesse social ou sem interesse clínico particular, como Jackendoff (1987) e Johnson-Laird (1988), para os quais o computacio-nalismo puro e a consciência subjetiva são totalmente compatíveis. Mesmo os neurofisiologistas (CRICK e KOCH, 1990) concordaram; esses constituem a artilharia pesada, já que aceitam a consciência por motivos materialistas. (FRAWLEY, 2000, p. 120).

Essas citações apontam para um outro aspecto que não será explicitamente desenvolvido neste texto, mas que seguramente permeia toda a nossa reflexão, a relação ciência e ideologia. Refletir sobre essa relação é crucial, quando se busca reconstruir uma perspectiva histórico-epistemológica sobre alguns fatos e teorias que abordam cognição e linguagem. Na verdade, procurar identificar a presença de um pensamento hegemônico na ciência moderna baliza, em grande parte, nossas reflexões sobre cognição, uma vez que “... a ciência é um saber ligado a grupos sociais determinados. A ciência moderna, em particular, liga-se à representação do mundo [...] Até que ponto consideramos eticamente aceitável que pessoas ou grupos veiculem ideologias sem se dar conta disso?" (FOUREZ, 1995, p. 190-191). ${ }^{11}$

${ }^{11}$ Essa questão, da relação entre ciência e ideologia, continua tendo extrema importância nos textos de epistemologia. Veja-se o exemplo de um seminário ocorrido na Itália em 1995, o qual discutiu como a ciência moderna "construiu nossa realidade" e originou o livro A construção da imagem científica do mundo - as mutações nas concepções do bomem e do cosmos desde o descobrimento da América até a mecânica quântica. Vários autores ligados à 
Buscar empreender tal reconstrução histórico-epistemológica a partir da cibernética é axial, uma vez que essa teoria se propôs a construir uma "nova ciência da mente" (DUPUY, 1996, p. 15, 45-52). Para isso, um grupo extenso e variado de pensadores passou a se reunir a partir de 1943, colocando para si a tarefa de encontrar respostas consistentes acerca do "funcionamento mental". Esse movimento acabou direcionando praticamente todos os estudos e pesquisas posteriores sobre cognição e linguagem:

O projeto teórico, ideológico e técnico (ciberneticista) moldou a nossa época como nenhum outro [...] introduziu a conceituação e o formalismo lógico-matemáticos nas ciências do cérebro e do sistema nervoso; concebeu a organização das máquinas de processamento de informação e lançou os fundamentos da inteligência artificial; produziu a "metaciência" dos sistemas, a qual deixou sua marca no conjunto das ciências humanas e sociais, da terapia familiar à antropologia cultural; inspirou fortemente inovações conceituais na economia, na pesquisa operacional, na teoria da decisão e da escolha racional, na teoria dos jogos, na sociologia, nas ciências do político e em muitas outras disciplinas; forneceu na hora certa a várias "revoluções científicas" do século XX -, muito diversas, pois vão da biologia molecular à releitura de Freud feita por Lacan -, as metáforas de que precisavam para assinalar sua ruptura em relação a paradigmas estabelecidos. (DUPUY, op. cit., p. 44).

Partindo da perspectiva de Dupuy de que o movimento ciberneticista ocupou um lugar central na história da ciência moderna, especialmente no veio que procura investigar a "mente", iremos ancorar nesta corrente teórica muitas de nossas reflexões acerca da relação cognição e linguagem, para prumar alguns fatos e teorias relacionados às pesquisas sobre tal relação. Nessa medida, é importante atentar para o fato de que, desde o início, o movimento ciberneticista foi vetor para um forte componente ideológico na ciência, qual seja, uma extrema valorização da lógica e da matemática para a compreensão da cognição e linguagem humanas, como estabelece, por exemplo, o texto de Dupuy, supra citado.

análise do discurso também se preocupam em investigar tal questão, tais como Fairclough (Cf. 1989, 1999; 2001) e Halliday (1993). Ou seja, sabe-se que o gênero discursivo científico pode agregar em si alto teor ideológico. 
Como as premissas ciberneticistas ainda hoje se espraiam nas ciências cognitivas, como, por exemplo, na inteligência artificial (IA, doravante), conexionismo, setores da psicologia cognitiva, biologia do conhecer, dentre outros, é importante perceber a influência dos trabalhos do Círculo de Viena ${ }^{12}$ para a constituição das primeiras discussões dos ciberneticistas a partir de 1943 (Cf. DUPUY, 1996). O ataque frontal à metafísica é um dos aspectos centrais desse grupo de pensadores, para os quais o saber científico não deve apenas "ser livre da metafísica, mas dirigida contra ela" (Cf. CALVET, 1997, p. 5). Outro aspecto central é a busca de uma linguagem universal, vale dizer, lógicomatemática, que unifique o campo das ciências (Ibidem, p. 17). Podese lembrar, ainda, das idéias de Turing e dos teoremas de Gödel. Todas essas proposições, que permearam as discussões do Círculo de Viena, anteciparam e orientaram a perspectiva ciberneticista, e ainda hoje orientam as principais, isto é, hegemônicas, vertentes das ciências cognitivas. Este quadro teórico mais amplo, ou seja, perceber a cibernética como um ponto de coalescência e ruptura para antigas questões que permeam a ciência e a filosofia ocidental, como a relação corpo-mente, permite-nos compreender a construção da metáfora computacional, isto é, através dessa metáfora toma-se o modelo, o computador, como referência para se investigarem os processos cognitivos bumanos.

Outra questão importante que encontramos, ao se fazer uma investigação epistemológica acerca da relação cognição e linguagem, é que, ao lado do tipo de limitação trazida pela metáfora computacional para pensar a cognição humana, muitas teorias, ao buscarem uma alternativa para tal metáfora, acabam resumindo no corpo ou fisiologia humana uma resposta para o que seja cognição, linguagem e consciência (Cf. TEIXEIRA, 2003, p. 51-63). Assim, tais teorias, para escapar da metáfora computacional, acabam adotando proposições

\footnotetext{
${ }^{12}$ Vários livros fazem essa relação entre as discussões que se fizeram a partir do Círculo de Viena sobre linguagem, especialmente, e como isso se espraiou pela comunidade científica, influenciando tanto behavioristas quanto ciberneticistas. Indicamos apenas alguns livros, Calvet de Magalhães, 1997: Filosofia analítica - de Wittgenstein à redescoberta da mente; Teixeira, 1998: Mentes e máquinas; Strathern, 2000, Turing e o computador em 90 minutos.
} 
construídas ao longo da modernidade, as quais sofreram um refinamento teórico no início do século XX, com a constituição da biologia como um campo da ciência, e que reduzem o ser humano à sua evolução biológica. Foi o que fez a psicologia comportamental, e veremos que essa "herança" evolucionista ${ }^{13}$ atravessa, por exemplo, as teorias da neurociência:

A possibilidade de desafiar a herança cartesiana no século XX foi, em grande parte, proporcionada pelo desenvolvimento da neurociência. Os neurocientistas, nas últimas duas décadas, têm persistentemente procurado soluções empíricas para os problemas da filosofia da mente - soluções que surgiriam de um estudo aprofundado do funcionamento do cérebro. Quase todos eles buscam o "desmascaramento" [...]; desmascaramento que mostraria, finalmente, que os chamados eventos mentais são eventos físicos ou cerebrais. (TEIXEIRA, 2003, p. 51).

Textos como os de António Damásio, alinhados à neurociência cognitiva, acabam revelando pressupostos epistemológicos construídos ao longo de toda a modernidade e que alcançam uma resolução "convincente" com a teoria evolucionista darwinista, quando reduz o ser humano a um "macaco especializado", isto é, somos animais e evoluímos biologicamente ao longo do tempo; isto define a "condição humana" e, portanto, seus processos cognitivos. Desde que Darwin postulou ${ }^{14}$ que "não há diferença fundamental entre o homem e os mamíferos superiores em termos de faculdade mentais" (Cf. SCHULTZ e SCHULTZ, 1992, p. 138), ocorrendo mesmo uma "continuidade no funcionamento mental entre os homens e os animais inferiores"

\footnotetext{
${ }^{13}$ Podemos lembrar que a própria lingüística tomou a teoria evolucionista de Darwin como parâmetro para assegurar seu caráter de cientificidade: "o que Darwin agora defende acerca da variação das espécies no curso do tempo [...] tem sido há muito tempo e em geral reconhecido em sua aplicação aos organismos da fala" (Cf. WEEDWOOD, 2002, p. 94).

${ }^{14}$ Encontramos na literatura epistemológica a defesa da idéia de que ocorreu na ciência moderna a construção ideológica da teoria evolucionista de Darwin. Há, por exemplo, o texto de Sermonti no qual o autor demonstra que Darwin era extremamente reticente em relação às suas idéias, e foi Haeckel que, "usando mais fantasia que raciocínio científico" imaginou um ser evoluindo de uma célula até a complexidade de um organismo (Cf. SERMONTI, 2002, p. 191-229).
} 
(SCHULTZ e SCHULTZ, 1992, p. 130), assistimos à montagem de um vasto "maquinário", por diversos ramos da ciência, o qual envolve a construção de teorias e pesquisas laboratoriais, "provando" tal continuidade. A psicologia comportamental, por exemplo, constituída no início do século XX, adotou a perspectiva evolucionista para compreender o ser humano, ou seja, a perspectiva comportamentalista defende que o comportamento humano é determinado pelas contingências ambientais (Cf. SKINNER, 1978, 1979, 1985, 1991; SCHULTZ e SCHULTZ, 1992, p. 268). Assim, Skinner adere à postulação darwinista de que a evolução humana é uma resposta ao ambiente: "durante uma longa série de gerações, as espécies se modificam [...] essas modificações efetuaram-se principalmente pela seleção natural de numerosas variações" ${ }^{15}$ (DARWIN, 2003, p. 450).

Como podemos ver, Skinner tem na teoria evolucionista um modelo para transformar a psicologia comportamental em uma "ciência": "a seleção natural e o condicionamento operante têm construído lentamente sua trajetória como explicações científicas" (SKINNER, 1991, p. 153). Destarte, a psicologia comportamental pôde reduzir o ser humano ao materialismo da ciência positivista:

o behaviorismo radical assenta-se sobre a negativa ontológica de existência de eventos imateriais, sem dimensões físicas, que se passem em um mundo não-físico. Sua premissa básica é, portanto, a de que só existem eventos materiais ocorrendo em um universo físico (ROSE, J. 1982, p. 68).

Caminho similar adota a neurociência, que parte do comportamento humano, de alguma disfunção, para compreender o que "há de errado", por exemplo, com a sua linguagem e cognição. "Considerando-se a dificuldade de raciocinar da neurobiologia básica para nosso

\footnotetext{
${ }^{15}$ Behe (1997), reforçando sua crítica à teoria evolucionista, relata a perspectiva de Lynn Margulis, bióloga ganhadora do prêmio Nobel, sobre a teoria evolucionista como uma "uma pequena seita religiosa do século XX" (Cf. BEHE, 1997, p. 35), uma vez que, para os críticos da teoria evolucionista, não há como provar que a evolução ocorra pelo "acúmulo de mutações". Mais adiante, nesse mesmo texto Behe cita paleontólogos, também críticos do evolucionismo: "não é de se espantar que os paleontólogos tenham ignorado a evolução por tanto tempo. Aparentemente ela jamais ocorre" (BEHE, 1997, p. 36).
} 
comportamento complexo, o darwinismo poderia ser uma base alternativa para entendermos a natureza humana" (ROSE, M. 2000, p. 194).

Esses breves apontamentos sobre a "evolução" históricoepistemológica de alguns pontos na ciência moderna, que desembocou no que passou a ser chamado de "revolução cognitiva", fazem emergir a urgência de repensarmos tal construção historiográfica. Ou seja, tais apontamentos nos colocam diante da questão: quais são as implicações teórico-sociais ocorridas a partir da constituição de um campo de saber como a cibernética e as ciências cognitivas? Somente a partir de um questionamento mais criterioso é que poderemos ampliar nossa compreensão sobre cognição, linguagem, aprendizagem e consciência, refutando a metáfora computacional como matriz compreensiva para a cognição e linguagem humanas e evitar modelos que procuram não só reduzir o ser humano à sua evolução biológica, mas ainda supor que a problemática da consciência possa ser resumida a uma referência ao social, exclusivamente, como fez Vigotski em seu texto Pensamento e linguagem. Vigotski conclui o livro Pensamento e linguagem dizendo que investigar a relação pensamento e linguagem levou a um tema axial para a psicologia, que é o da compreensão da consciência. Nessa obra o autor procurou mostrar que "o pensamento surge pelas palavras" (PERFEITO, 1999, p. 86), sendo que "a palavra é um microcosmo da consciência humana" (VIGOTSKI, 2003, p. 190). Assim, podemos ver que a consciência, para Vigotski, é dada pelo social.

Acredito que a construção de um modelo científico que consiga superar os paradoxos e limitações existentes nas bases epistemológicas da ciência moderna, conforme temos apontado, pode ser alcançado através de um esforço conjunto da LC e da psicologia cognitiva ao repensarem os conceitos aqui destacados.

\section{Contextualização histórica da construção da interface entre a Lingüística e Psicologia para compreender a cognição e a linguagemhumanas}

Tão logo a lingüística e a psicologia se constituíram como disciplinas da ciência moderna, no início do século XX e na segunda metade do século XIX, respectivamente, nasceu entre ambas uma busca espontânea por um diálogo que formalizasse os aspectos teóricos que abarcavam os dois campos de conhecimento. 
Wilhelm Wundt, "fundador" da psicologia acadêmica em 1879, desenvolveu trabalhos na área da psicologia cultural, nos quais buscava investigar algumas mudanças que ocorrem na linguagem e sua relação com alguns aspectos cognitivos. Tal perspectiva pode ser considerada como precursora tanto da LC como da psicologia cognitiva (Cf. SINHA, 2001, p. 5). Wundt considerava, ainda, a lingüística uma disciplina complementar à psicologia, podendo lhe fornecer uma base metodológica consistente (Cf. SINHA, 2001, p. 5). Há ainda os trabalhos de Ebbinghaus e Külpe, este último ligado à Escola de Würzburg, nos quais, esses psicólogos investigaram alguns processos cognitivos superiores, como memória e pensamento, empregando a lingüística enquanto método de pesquisa (Cf. SCHULTZ e SCHULTZ, 2005, p. 91-96; 99-103; GARDNER, 1996, p. 119).

Em dezembro de 1928, Sapir formulava o seguinte desafio:

A lingüística constitui um campo de pesquisa ao mesmo tempo dos mais difíceis e dos mais fundamentais. É provável que ainda nos aguarde no futuro uma integração realmente frutuosa dos estudos lingüísticos com os psicólogos. É de suspeitar que a lingüística está destinada a ter um valor todo especial para a psicologia configurativa (ou Psicologia da Gestalt) (SAPIR, 1969, p. 24).

Contudo, como se sabe, uma associação formal entre a lingüística e a psicologia só ocorreu em 1954, com a constituição da Psicolingüistica na ciência americana, a partir dos seminários em Cornell, nos Estados Unidos, em 1951 e 1953 (MELO, 1999, p. 17). Nesse contexto histórico, as críticas formuladas por Chomsky ${ }^{16}$ à psicologia comportamental foram axiais para um questionamento de seus pressupostos epistemológicos,

\footnotetext{
${ }^{16}$ Paradoxalmente, mesmo Chomsky tendo atacado um dos bastiães da ciência moderna, a Psicologia Comportamental, ele, simultaneamente, tornou-se um dos representantes mais expressivos do paradigma da ciência moderna. Há, inclusive, semelhança entre suas proposições e as do comportamentalismo, como por exemplo, o que esse autor propõe para a aprendizagem: "aprender é, antes de tudo, uma questão de preencher detalhadamente uma estrutura que é inata" (CHOMSKY, 1980, p. 35). Chomsky chega mesmo a propor que o espírito seja reduzido a uma estrutura biológica: "nossos sistemas de crença são os que o espírito, enquanto estrutura biológica, está destinado a cumprir." (Ibidem, p. 12).
} 
iniciando um movimento de confronto com o pensamento hegemônico comportamentalista. Pode-se mesmo compreender que os avanços dos estudos da lingüística exigiram que os psicólogos revissem uma série de pressupostos teóricos da psicologia (Cf. MELO, 1999, p. 14; ANDERSON, 2004, p. 6). Basta lembrar que o termo e a disciplina de psicologia cognitiva somente foram propostos por Ulric Neisser em 1967, ou seja, após mais de uma década de estudos da psicolingüística. A quebra da hegemonia comportamentalista possibilitou também a ampliação da divulgação do trabalho e pesquisa de outras vertentes da psicologia, como, por exemplo, a psicologia da gestalt. A partir desse momento, a psicologia cognitiva volta a pesquisar, de forma sistematizada, aspectos dos "processos mentais" presentes nas origens da psicologia moderna, tais como pensamento, memória, aprendizagem, percepção, solução de problemas, dentre outros tópicos. Contudo, o problema da consciência, questão presente nos primórdios da psicologia com Wundt, ${ }^{17}$ continuou "banido" de seu campo de pesquisa, uma vez que as ciências cognitivas rejeitaram essa questão como problema para a ciência. Tal rejeição se deveu, em grande parte, à influência que o Círculo de Viena exerceu sobre a cibernética, ao recusar discutir questões metafísicas, conforme salientamos. Contudo, se esta perspectiva tem mudado significativamente desde o final da década de 1980 (Cf. SEARLE, 1998; TEIXEIRA, 2003, p. 153), defendemos que é essencial refletir como essa discussão acerca da consciência "voltou" para o campo das ciências cognitivas.

Como temos visto, ao longo da histórica a ciência, tanto a lingüística quanto a psicologia buscaram uma complementação teóricometodológica para investigarem a cognição e a linguagem. A psicolingüística apresentou "um vasto programa de pesquisas inspiradas por uma tentativa de síntese da psicologia do aprendizado, teoria da informação e da Lingüística" (MELO, 1999, p. 17). Podemos ver na LC, também, a busca de uma associação mais estreita com a psicologia cognitiva. O impulso inicial para o estabelecimento da LC como um campo teórico específico, veio de trabalhos como os de Eleanor Rosch,

\footnotetext{
${ }^{17}$ Schultz e Schultz defendem que o objeto de estudo da Psicologia de Wundt é a consciência: "o objeto de estudo de Wundt consistia, para definir em uma única palavra, na consciência”. (Cf. SCHULTZ e SCHULTZ, 2005, p. 83).
} 
psicóloga cognitiva, sobre a "natureza da categorização humana" (Cf. JANDA, 2000, p. 2). Langacker dá um passo além para essa aproximação da lingüística e da psicologia ao afirmar que é necessário "construir" modelos psicológicos que abordem aspectos da linguagem para que sejam empregados na LC, pois como comenta o autor, esses modelos não estão repousando nas prateleiras da psicologia ou inteligência artificial (LANGACKER, 1987, p. 1-7). A LC, ou, Langacker (Ibidem, p. 1-7) entende que é urgente e vital para a teoria lingüistica repensar sua fundação conceitual, acrescentando, ainda, que a LC tem o interesse singular na compreensão de como se dá a construção de significado (LANGACKER, 1987). Destarte, com a volta da discussão do conceito de consciência para o campo das ciências cognitivas, é preciso que esse novo modelo, a ser construído, encampe o conceito de consciência, como produtor, por exemplo, de significado.

Como tenho defendido ao longo do texto, a "volta" da discussão do conceito de consciência proposto pelas ciências cognitivas enseja uma investigação epistemológica da associação entre a lingüística e a psicologia, a qual poderá ajudar a superar algumas premissas paradoxais formuladas ao longo da constituição da ciência moderna. Algumas dessas premissas são comentadas abaixo, com a intenção de ampliar a compreensão da relação cognição e linguagem, bem como dos conceitos de consciência e aprendizagem.

\section{Buscando algumas razões para a refutação do conceito de consciência pelas ciências cognitivas até fins dos anos de 1980}

Para ampliar a compreensão acerca das inovações, rupturas, interdições herdadas do movimento ciberneticista pelas ciências cognitivas, é imprescindível que fiquemos atentos à tese de Dupuy de que "as ciências cognitivas têm vergonha de seu passado cibernético" (DUPUY, 1996, p. 10), passado esse que envolveu uma recusa a abordar problemas ligados à metafísica e, portanto, a pesquisar temas como a consciência, conforme foi dito acima.

Dimensionar o significado dessa proposição de Dupuy demandanos contextualizar, minimamente o que representou o modelo comportamental na psicologia, não só em função da aproximação que 
Dupuy faz entre o movimento cibernético e a psicologia comportamental (Cf. DUPUY, 1996, p. 47-48), mas, principalmente, devido ao significado que têm as proposições comportamentalistas para a ciência moderna de maneira geral, uma vez que a proposta teórica da psicologia comportamental pode ser compreendida como uma "conclusão" para o silogismo iniciado com Descartes no século XVII.

Penna (2003, p. 14), citando Hearnshaw, ressalta que a modernidade significou uma desvalorização da racionalidade, da investigação sobre os "processos mentais" e da relação entre pensamento, linguagem e consciência. A psicologia comportamental representa uma das correntes teóricas mais consistentes nesse sentido, "uma versão refinada do vernáculo para o estudo da vida mental não é mais útil do que a versão leiga, principalmente quando a teoria começa a substituir a introspecção" (Cf. SKINNER, 1990, p 5). Esta assertiva de Skinner, feita na semana de sua morte em1990, ajuda-nos a perceber a estreita ligação entre o Círculo de Viena e a psicologia comportamental (Cf. TREVISAN, 1982, p. 32-64). Em 1932, dois textos publicados por Carnap, A superação da metafísica mediante a análise lógica da linguagem e Psicologia em linguagem fisicalista, dão a dimensão da estreita ligação entre a psicologia e os filósofos que, ligados ao Círculo de Viena, buscavam compreender a mente, reduzindo-a ao cérebro. Segundo Carnap,

toda proposição de Psicologia pode ser formulada em linguagem fisicalista [...] todas as proposições da Psicologia descrevem acontecimentos físicos [...] Nossa tese afirma [...] que para todo conceito [...] psicológico é possível formular uma definição que, direta ou indiretamente, o reduza a conceitos físicos. (apud TREVISAN, 1982, p. 41-42).

Tais referências ajudam-nos a contextualizar o que temos defendido ao longo do texto: o início do século XX representou para o desenvolvimento da ciência moderna a generalização e naturalização ${ }^{18}$

${ }^{18}$ Emprego esse conceito na mesma acepção de Fairclough (2003, p. 94), quando esse autor aponta para o fato de que o discurso, ao encampar convenções, transforma o que é ideológico e hegemônico em um discurso universal e naturalizado. Aqui me refiro especificamente ao gênero discursivo científico, o qual realiza a característica da invisibilidade do discurso begemônico com extrema eficiência, isto é, não permite ver o que é particular, ligado a interesses "locais" da sociedade no geral (Cf. FAIRCLOUGH, 1989, p. 77-93). 
do paradigma do modelo para o ser humano como autômato. A entrada dessa proposição nos Estados Unidos deu-se através da cibernética, que tem um enraizamento profundo no Círculo de Viena, conforme defendemos anteriormente, e podemos acrescentar ainda que a psicologia comportamental, especialmente em sua versão radical com Skinner, foi outra porta de entrada para a naturalização do paradigma da ciência moderna do ser humano como autômato em solo americano. Skinner, relatando a sua proximidade com o positivismo lógico, escreveu que

meu compromisso era com o empirismo lógico de Ernst Mach. Se, por um lado, pode-se dizer que o positivismo lógico começou com o primeiro número de Erkenntnis, eu progredi o suficiente em minha carreira para garantir para mim mesmo o privilégio de ser o equivalente americano de seu Philosophy of Science [...] Carnap suscitou a questão de que estaríamos falando sobre um robô que se comportava como gente, e que isso soava como comportamentalismo, mas eu discordava do tratamento dado às idéias, sensações, sentimentos e outros assim chamados estados da mente. Os positivistas lógicos, a exemplo de alguns comportamentalistas metodológicos (incluindo Boring e Stevens), admitiam a existência de uma mente, mas estabeleceram que ela estava fora do domínio da ciência, visto não poder ser confirmada por uma segunda pessoa. Eu preferi o comportamentalismo radical que aceitava a existência de eventos internos, porém como estados corporais; seu estudo deveria ser deixado a cargo da fisiologia. Dados obtidos através da introspecção seriam insuficientes para a ciência, uma vez que a privacidade torna impossível aprender a observá-los de maneira precisa. (SKINNER, 1991, p. 149).

Essas colocações de Skinner justificam a compreensão que se tem da psicologia comportamental como fisicalista, ou seja, os estados mentais podem ser resumidos aos estados cerebrais (Cf. ABIB, 1982, p. 92-109). Procurar demonstrar que o ser humano pode ser completamente compreendido por seus aspectos biológicos é uma das colunas de sustentação da ciência moderna, bem como da perspectiva fisicalista, que é extremamente forte dentro das ciências cognitivas.

A ciência moderna tem se caracterizado por uma valorização de perspectivas e teorias de cunho empirista e pragmático Penna (2003, p. 13-39). É nesse quadro teórico mais geral que podemos encontrar a redução que a psicologia comportamental faz do ser humano à sua biologia. Na verdade, tal redução comportamentalista realiza a conclusão 
de um silogismo que tem a sua premissa maior estabelecida por Descartes de que "os animais são autômatos". Dando continuidade a esse silogismo, Darwin estabelece a premissa menor de que o homem é apenas um animal, um "macaco especializado", e temos a conclusão de tal silogismo com a formulação de Watson, "fundador" da psicologia comportamental nos Estados Unidos, em 1913, de que o homem é um "autômato", uma vez que ele é um animal e aprende, exclusivamente, através de estímulo e resposta. O modelo para o ser humano proposto pela psicologia comportamental é o da máquina que é movida através de estímulo e resposta (input e output). Podemos encontrar no texto de Skinner Ciência e comportamento bumano, de 1953 (Cf. SKINNER, 1985), a proposição do homem-máquina, através da qual o autor aproxima o homem da máquina,

[...] o homem criou a máquina à sua própria imagem. E como resultado, os organismos vivos perderam algo de sua singularidade [...] Ao mesmo tempo, descobrimos mais sobre como funciona o organismo vivo e somos mais capazes de reconhecer as propriedade que têm em comum com as máquinas.

Destarte, há uma proximidade muito grande entre a psicologia comportamental e a cibernética, como aponta Dupuy (op. cit.). Devemos manter essa proximidade em nosso horizonte analítico, para ajudar-nos a compreender os rumos que as ciências cognitivas têm tomado e, principalmente, quais são os seus pressupostos epistemológicos e ontológicos e como esses pressupostos irão conduzir as investigações sobre o conceito de consciência.

O modelo do homem-máquina permeou também toda a primeira cibernética, 1943-1956 (Cf. DUPUY, 1996), bem como acabou prevalecendo como ontologia para o cognitivismo, inaugurado em Dartmouth, nos EUA, em 1956. Em 1953 McCulloch propôs que "as máquinas feitas pela mão do homem não são cérebros, mas os cérebros são uma variedade muito mal compreendidas de máquinas computacionais" (DUPUY, 1996, p. 54). Vale notar que mesmo Lacan, psicanalista de destaque entre os anos de 1950-1980, ciberneticista de primeira ordem, também tem a pretensão de mecanizar o ser humano, ou tem a intenção de demonstrar que a linguagem humana pode ser compreendida como um cálculo. Assim, proferiu uma conferência em 1955, cujo título é Psicanálise e cibernética, ou da natureza da 
linguagem" (Ibidem, p. 140), já em 1954 Lacan defendia que "o mundo simbólico é o mundo da máquina” (Ibidem, p. 195). Tal perspectiva acompanhou Lacan por toda a sua vida, ${ }^{19}$ pois em 1978 ele ainda defende que “... saber se [a máquina] é ou não humana está, evidentemente, totalmente resolvida - ela não o é. Só que é preciso também saber se o humano, no sentido em que vocês o entendem, é tão humano assim" (Ibidem, p. 143).

O que procuro explicitar neste momento é que essa ontologia construída acerca do ser humano resumido a processos mecânicos e biológicos e desprovido de uma "essência" é uma construção histórica que tem nas proposições da fisiologia moderna a sua origem. Ao longo de toda a modernidade, os fisiologistas buscaram demonstrar que a Alma, ou qualquer tipo de princípio vitalista, não era responsável pelos movimentos do corpo (PESSOTTI, 1982). "A partir de 1680, com os iatromecânicos italianos, geniais criadores de uma anatomofisiologia fundada na matemática e na mecânica de Galileu" (PESSOTTI, 1982, p. 17), todos os movimentos corporais eram causados por processos orgânicos internos ao organismo. Assim, todo um arcabouço teórico e de pesquisas foi conduzido para se poder concluir que "a Alma não tem função alguma no processo da contração (muscular)" (Ibidem, p. 18). Destarte, a partir da modernidade, o ser humano é entendido como um organismo que através de suas interações com o ambiente consegue criare manter a sua própria vida através da auto-regulação (FIGUEIREDO, 1991, p. 73-124). Dito de outra forma, abandona-se a idéia da transcendência para se adotar, na modernidade, a crença da imanência. Como sabemos, atualmente essas causas internas são explicadas através dos neurotransmissores pela neurociência, por exemplo.

A idéia da autoregulação foi desenvolvida por biólogos desde a década de 1920, para escapar ao determinismo ambientalista (Cf. FIGUEIREDO, op. cit.) e tornou-se um conceito axial não só para a biologia, mas para as ciências cognitivas em especial. Como lembra Dupuy (1996, p. 99, 132-133), a segunda cibernética inaugura-se, exatamente, com a idéia da auto-regulação, que teve sua origem conceitual entre os biólogos, como dissemos. Não há coincidência,

${ }^{17}$ Lacan morreu em 1981. 
portanto, que os trabalhos de Maturana e Varela (ambos biólogos) desenvolvam o conceito de auto-organização e, junto ao conexionismo e à nova robótica representem pontos altos desse ideal ciberneticista (Cf. DUPUY, op. cit.; FIGUEIREDO, 1991, p. 93, 110-111) e da própria ciência moderna, como temos procurado demonstrar. Ideal que pode ser entendido como a busca de transformar o ser humano em seu autoprodutor, ou o criador de si próprio, encerrado em uma anatomofisiologia que, através de interações ambientais, naturais e sociais, é capaz de se criar e manter. ${ }^{20}$

Todos esses trabalhos (Biologia do Conhecer, Conexionismo, Nova Robótica) [...] têm um ponto comum. Tratam uma rede complexa de calculadoras elementares em interação com um ser "autômato" [...] Como todo autômato de estado interno, uma rede calcula seu estado na época seguinte em razão de seu estado presente (DUPUY, 1996, p. 133-134).

Ao analisarmos essa ontologia humana construída ao longo da modernidade a partir da proposta de Thomas Kuhn para compreender o que é a ciência normal, podemos inferir que chamar os estudos hegemônicos sobre cognição e linguagem de "revolucionários" é, acima de tudo, uma construção ideológica. Para Kuhn,

a ciência normal, atividade que consiste em solucionar quebracabeças, é um empreendimento altamente cumulativo, extremamente bem-sucedido no que toca seu objetivo, a ampliação contínua do alcance e precisão do conhecimento científico ... A ciência normal não se propõe a descobrir novidades no terreno dos fatos ou da teoria; quando é bem-sucedida não as encontra (KUHN, 2001, p. 77) (grifo da autora).

Como temos procurado demonstrar, tanto a psicologia comportamental quanto vários "ramos" das ciências cognitivas, tais como

\footnotetext{
${ }^{20}$ Hannah Arendt, em seu livro A Vida do Espírito (1993, p. 162), denuncia que "as noções marxistas e existencialistas [...] que fazem crer que o homem é o seu próprio produtor e criador - baseiam-se nessas experiências, embora seja claro que ninguém jamais tenha "criado" a si mesmo ou "produzido" a sua existência; esta, penso eu, é a última das falácias metafísicas, que corresponde à ênfase que a Era Moderna faz recair sobre a vontade como substituta do pensamento" (grifo da autora).
} 
conexionismo, nova robótica, biologia do conhecer e inteligência artificial, representam, dentro da ciência moderna ocidental, o que Kuhn (op. cit.) chama de ciência normal, à medida que, através de vários refinamentos teórico-metodológicos, estabeleceram, de forma consistente, a ontologia na qual o ser humano é um autônomo que se auto-regula através de interações com o meio social e natural.

A obra seminal de Koyré também é decisiva para que possamos compreender esse tipo de construção ontológica e epistemológica da ciência moderna ocidental. O autor defende que as bases fundacionais da ciência moderna envolvem um diálogo contínuo com o pensamento religioso, "para nele inspirar-se, quer para refutá-lo" (KOYRÉ, 1991, p. 10). Ou seja, conforme vimos, as pesquisas dos fisiologistas modernos foram orientadas de forma a combater a idéia da Alma como "causa" de animação para o corpo. Seguramente o que temos procurado destacar é que esse modelo proposto pela ciência moderna para compreender o ser humano como um "autônomo", regulado por leis oriundas de sua fisiologia, evolução biológica e de suas relações com o contexto social, não consegue abarcar outros fenômenos humanos, como o da consciência, por exemplo, uma vez que a consciência não pode ser reduzida a nenhuma dessas instâncias. Ao lado disso, esse modelo apresenta um fortíssimo componente ideológico, expresso através da idéia do ser humano autônomo que não está submetido a nenhum tipo de lei que não possa ser extraída da matéria, ${ }^{21}$ e que, portanto, não possa ser mensurável e localizável.

A psicologia comportamental, a cibernética e as ciências cognitivas de forma geral podem ser compreendidas, portanto, como saberes científicos que "naturalizaram" 22 o projeto da ciência moderna de construir uma ontologia humana que se afaste completamente da referência medieval, isto é, "trata-se da substituição do teocentrismo

\footnotetext{
${ }^{21}$ Adotar essa perspectiva da matéria como algo estritamente "concreto" é também uma escolha ideológica, pois há décadas filósofos e físicos apontam para o fato de que "o ponto material é uma abstração matemática à qual nos habituamos e à qual acabáramos por atribuir uma realidade física. É ainda uma ilusão que devemos abandonar", como, por exemplo, propôs Cartan (apud BACHELARD, 1985, p. 114).

22 Ver nota 12.
} 
medieval pelo ponto de vista bumano; da substituição, pelo problema moral, do problema metafísico e, também, do problema religioso; da substituição do problema da salvação pelo ponto de vista da ação" (KOYRÉ, 1991, p. 18), ou ainda, como coloca Burtt (1983, p. 98), "O cientista escolástico defronta-se com o mundo da natureza, o qual lhe parecia receptivo e humano. O mundo era finito [...] Agora (na modernidade) o mundo é uma máquina matemática infinita e monótona" (grifo da autora). Contudo, o projeto da ciência moderna encontra-se também eivado ideologicamente e, como sabemos, a partir dos trabalhos de Foucault (apud FAIRCLOUGH, 2003, p. 61-88), dentre outros, há um vínculo muito estreito entre conhecimento e poder:

o poder moderno não foi imposto de cima por agentes coletivos específicos (por exemplo, classes) sobre grupos ou indivíduos; ele se desenvolveu debaixo, em certas microtécnicas [...] Tais técnicas implicam uma relação dual entre poder e conhecimento na sociedade moderna (Ibidem, p. 75).

O que temos proposto, então, é que a chamada "revolução cognitiva" foi, acima de tudo, uma construção da história de um ramo da historiografia científica, e uma realização da ciência normal, que deu continuidade à construção e "naturalização" do paradigma moderno para o ser humano como um autômato. Sendo assim, a cognição humana pode se resumir a processos lógicos e inferenciais que se autoalimentam e que, de preferência, possam ser "mapeados" através das atividades cerebrais. Com isto, a cognição pode ficar reduzida à biologia humana. Destarte, toda a discussão metafísica teria que ser descartada, o que efetivamente ocorreu com a cibernética, que buscou construir "uma mente sem sujeito" (Cf. DUPUY, 1996, p. 138). A metafísica máxima que se teria, segundo Heidegger, seria, então, aquela na qual "a cibernética é a metafísica da era atômica" (Ibidem, p. 111). Temos então o coroamento da máquina, processos lógicos, redes neurais, em detrimento de questões mais humanas, como por exemplo, o fenômeno da consciência: "a cibernética foi um dos principais instrumentos desestabilizadores da concepção antropocêntrica do homem", segundo Breton (apud DUPUY, op. cit., p. 141).

Conforme ressaltamos, é essencial que fiquemos atentos às bases epistemológicas fundacionais das ciências cognitivas, nas quais a consciência teria que, necessariamente, ficar ausente da discussão 
sobre cognição bumana, uma vez que "pensar é calcular". É essencial, ainda, que fiquemos atentos ao passado ciberneticista das ciências cognitivas, porque as discussões históricas acerca dos discursos ideológicos e hegemônicos mostram, claramente, que, quando o discurso hegemônico se apropria de um conceito, ele o faz de forma que sirva aos seus interesses, ou seja, retira do conceito todo o seu potencial inovador e criativo (Cf. LACLAU e MOUFFE, 1985). Nessa medida, conforme veremos abaixo, de forma geral, esse já tem sido o "destino" que diferentes setores das ciências cognitivas têm dado ao conceito de consciência, ao pretender reduzi-la a eventos cerebrais ou redes neurais, como faz Damásio, através do arcabouço teórico da neurociência cognitiva.

Damásio, em O mistério da consciência, depois de relatar vários casos clínicos sobre pacientes que sofreram "lesões cerebrais", acredita que, "passando à possível biologia subjacente à consciência central, [...] um conjunto de estruturas e operações neurais [...] pode alicerçar a emergência do sentido do self e do conhecimento" (DAMÁSIO, 2000, p. 247), ou seja, o mistério da consciência será desvelado quando esta for "localizada" no cérebro. Assim, para a neurociência cognitiva "não se pode mais estudar a mente sem estudar o cérebro, pois acredita-se cada vez mais que suas características seriam a chave para a compreensão da natureza da cognição e da consciência" (TEIXEIRA, 2003, p. 173). Há ainda o setor das ciências cognitivas ligado à inteligência artificial, que propõe uma compatibilidade entre computacionalismo e consciência conforme defende Johnson-Laird (apud FRAWLEY, 2000, p. 120). Ficaria a consciência resumida, então, a um cálculo computacional e inferencial.

$\mathrm{Na}$ última seção do texto, procuro mostrar que esta discussão acerca da consciência sempre esteve presente em algumas correntes não hegemônicas da psicologia, desde a sua origem. Assim, retornamos à nossa questão recorrente: é possível que a associação entre a lingüística, especificamente a LC, e a psicologia cognitiva consiga construir um modelo para a aprendizagem que leve em consideração a consciência, sem que esta seja reduzida a rede neurais ou a cálculos e inferências? Acredito que: revolucionária seria a possibilidade de construir um modelo científico para pensar cognição, linguagem, consciência, aprendizagem e outros aspectos humanos, de forma a romper com toda essa perspectiva da ciência moderna. 


\section{A consciência vista por alguns estudos não hegemônicos dentro da Psicologia}

Na virada do século XIX para o século XX, desenvolveu-se uma corrente teórico-metodológica que tinha por base a recusa do projeto científico moderno. Tal corrente é expressa pela associação da fenomenologia e gestalt que procurou "rejeitar a valorização inadequada e puramente dogmática dos elementos sensíveis como os únicos a concederem fundamentação rigorosa ao saber" (PENNA, 1982, p. 137) (grifo da autora). Nessa medida, tanto os gestaltistas ${ }^{23}$ quanto os defensores das teses fenomenológicas não reduziram o corpo humano à sua anatomia e fisiologia, nem mesmo procuraram ver nele uma dinâmica de causalidade, como aquelas propostas pela associação entre estímulo-resposta, input-output, pois isso promoveria a reificação desse corpo, "nivelando-o aos objetos que o cercam" (Cf. PENNA, 1997, p. 147). Para escapar a tal reificação, Merleau-Ponty, ${ }^{24}$ por exemplo, desenvolveu o conceito de corpo próprio, através do qual buscou introduzir a noção existencial desse corpo, ou seja, o que se pretende nessa perspectiva teórica é encontrar uma maneira, uma metodologia, que permita que a essência (eidos) dos sujeitos e objetos se manifeste. É nesta medida que a psicologia da gestalt pode ser compreendida como a corrente dentro da psicologia que procurou desenvolver uma metodologia fenomenológica. "Cabe, ainda, assinalar que a relevância concedida pela teoria da "gestalt" ao estudo da percepção decorreu rigorosamente da tese fenomenológica que atribuiu à consciência perceptiva a condição de forma suprema de manifestação da consciência" (PENNA, 2001, p. 70). Como se vê, a psicologia da gestalt mantém a discussão sobre a consciência firmemente enraizada em sua teoria e

\footnotetext{
${ }^{23}$ A psicologia da Gestalt se constitui precisamente devido à sua discordância dos pressupostos teóricos comportamentalistas (Cf. KOFFKA, 1975, p. 15-35).

${ }^{24} \mathrm{O}$ conceito de corpo próprio desenvolvido por Merleau-Ponty insere-se na discussão mais ampla da relação corpo-mente (Cf. Penna, 1997, p. 145-159), discussão que permeia toda essa problemática que temos abordado, uma vez que essa proposição cartesiana encontra-se na origem da ciência moderna. E conforme dissemos, a discussão da relação corpo-mente é um dos problemas precípuos berdados pela psicologia.
} 
busca desenvolver uma metodologia que consiga abarcar tais fenômenos humanos. Por outro lado, a neurociência cognitiva, representada no trabalho de Damásio, pretende demonstrar que é possível reduzir a consciência a processos cerebrais, conforme veremos adiante.

A psicologia da gestalt encontra-se na origem da psicologia cognitiva: "com o gestaltismo temos ingresso no campo específico da psicologia cognitiva" (Cf. PENNA, 1999, p. 25). Contudo, como se sabe, a gestalt não pertence à corrente hegemônica da psicologia, nem das ciências cognitivas. Essa observação é fundamental porque, levando em consideração a frase do início do texto "a teoria determina o que podemos observar" e sabendo que ciência normal trabalha para demonstrar a veracidade daquilo que a teoria postula, é urgente rever a premissa de que a consciência pode ser encontrada na neurofisiologia humana. Assim, procuraremos argumentar, através do cotejo do relato que Damásio (2000) faz de pacientes que sofreram acidentes cerebrais e da perspectiva da psicologia cognitiva, o quanto as referências teóricas podem limitar o fenômeno investigado.

No capítulo 4 de O mistério da consciência, Damásio relata alguns casos clínicos de pacientes que sofreram acidentes cerebrais, procurando compreender a relação entre linguagem e consciência. Damásio propõe que

a idéia de que o self e a consciência emergem depois da linguagem e são uma construção direta da linguagem provavelmente é incorreta. A linguagem não vem do nada [...] Se o self e a consciência, por sua vez, nascessem da linguagem, seriam o único exemplo de palavras sem um conceito subjacente [...] A linguagem contribui de modo essencial para a forma de consciência de alto nível [...] Por esse motivo, é preciso de fato um grande esforço para imaginar o que fundamenta a linguagem, mas esse esforço tem que ser feito (DAMÁSIO, 2000, p. 145).

Diante desse tipo de entendimento e desafio, Damásio relata que uma paciente, mesmo tendo desenvolvido afasia em função de uma doença neurológica, manteve intacta sua consciência: "sua linguagem já não estava à altura do refinamento de seu processo de pensamento [...] (contudo) ela apreendeu de imediato todos os níveis de significado implícitos naquela imagem icônica [...] achei comovente aquela prova de consciência!" (Ibidem, p. 150). Damásio propõe mais à frente, nesse texto, que 
o fato de a consciência central ser separável de outros processos cognitivos não significa que a consciência não exerce influência sobre eles. Pelo contrário, [...] a consciência central focaliza e intensifica a atenção e a memória operacional [...] é indispensável para as operações normais da linguagem (Ibidem, p. 165).

Os relatos e observações de Damásio nos permitem inferir que a consciência é uma instância "superior" que regula a linguagem e os outros processos cognitivos, o que por si só justifica a absoluta necessidade de se procurar compreender de forma menos restritiva o fenômeno da consciência. Contudo, parece que, simultaneamente e paradoxalmente, esse autor reduz a consciência a um processo cognitivo, voltando a igualar cognição e consciência, pois a neurociência cognitiva reduz as cognições a eventos cerebrais, logo, a consciência só pode ser abordada pela neurociência cognitiva se, e somente se, também puder ser abordada dessa maneira, isto é, a consciência também precisa ser "encontrada" nas redes neurais: "o problema da consciência na perspectiva da neurobiologia [...] é descobrir como o cérebro produz padrões neurais" (DAMÁSIO, 2000, p. 25). O paradoxo, então, encontra-se no fato de Damásio atribuir à consciência uma "função" superior às cognições, e, ao mesmo tempo, afirmar que ela apresenta a mesma "qualidade" das demais cognições humanas.

Essa forma de compreender a consciência aproxima algumas idéias do autor às de William James, desenvolvidas no final do século XIX, como aponta o próprio Damásio (Ibidem, p. 250). Destarte, podemos reencontrar no texto de Damásio a realização do paradigma de ciência moderna, ao encerrar o ser humano em um corpo "neurobiológico" que se auto-regula:

em sua operação normal e ótima a consciência central é o processo de obter um padrão neural e mental que reúne, aproximadamente no mesmo instante, o padrão para o objeto, o padrão para o organismo e o padrão para a relação entre ambos. A emergência de cada um desses padrões e sua conjugação no tempo dependem das contribuições de sítios cerebrais individuais trabalhando em estreita cooperação [...] Exatamente como William James teria desejado, quase todo o cérebro é mobilizado no estado consciente (Ibidem, p. 149-250).

James, considerado precursor da psicologia funcionalista (Cf. SCHULTZ e SCHULTZ, 2005; MARX e HILLIX, 1997; FADIMAN e FRAGER, 
1979), aderiu fortemente aos pressupostos da teoria evolucionista darwiniana, o que significa dizer que o ser humano deve ser compreendido em termos de uma evolução biológica:

James enfatizou a finalidade da consciência [...] ele foi muito influenciado pela nova teoria evolucionária e achava que a consciência deve ter alguma utilidade biológica [...] A distribuição da consciência mostra-nos que esta é exatamente como poderia esperar-se de um órgão adicionado com o propósito de orientar um sistema nervoso que se tornou demasiado complexo para regular-se a si próprio. (Cf. MARX e HILLIX, 1997, p. 194).

Cotejando as proposições de Damásio feitas em 2000 e as de James feita em 1890, podemos encontrar com clareza o conceito de ciência normal proposto por Kuhn, supra citado. O que é importante destacar neste momento é que, como temos defendido, os ramos hegemônicos das ciências cognitivas continuam desenvolvendo e refinando os pressupostos ontológicos e epistemológicos propostos pela ciência moderna desde, pelo menos, o século XVII. Como propôs Kuhn,

talvez a característica mais impressionante dos problemas normais da pesquisa [...] seja seu reduzido interesse em produzir grandes novidades [...] a ciência normal não se propõe descobrir novidades no terreno dos fatos ou da teoria [...] (devido) à existência de uma sólida rede de compromissos ou adesões - conceituais, teóricas, metodológicas e instrumentais (KUHN, 2001, p. 55, 65, 77).

Essa continuidade entre os trabalhos de James e Damásio demonstra, portanto, o quão fundamental é, para o desenvolvimento da ciência, a existência de um pacto entre os cientistas para a realização da ciência "como um lugar de comprometimento profissional, anterior aos vários conceitos, leis, teorias e pontos de vista que delas podem ser abstraídos" (Ibidem, p. 31). Na verdade, ambos os trabalhos se desenvolveram porque durante toda a modernidade construiu-se o modelo do bomem autômato. Segundo Kuhn (op. cit.), a comunidade científica firmou um pacto, ou tal pacto foi construído ao longo dos séculos, que depois de estabelecido, possibilitou que a comunidade científica fosse aderindo a leis, conceitos, teorias que possibilitaram a construção e naturalização do modelo do autômato.

Mesmo que o desenvolvimento da ciência normal seja essencial para que a ciência avance, é necessário questioná-la nos momentos 
em que a sua reprodução passa a significar um entrave para o desenvolvimento da compreensão dos fenômenos sobre os quais a ciência se debruça. Parece-nos que isso é o que o que tem ocorrido com o fenômeno da consciência, ou seja, os modelos propostos para compreendê-lo, como os da inteligência artificial e conexionismo, são vetores de uma teoria dada a priori, a qual foi constituída, como vimos, em uma dinâmica teórico-metodológica de forma a excluir o conceito de consciência. Para que possamos estabelecer esse tipo de formulação, é imprescindivel que tenhamos como referência histórico-epistemológica a antecedência das discussões do Círculo de Viena, da psicologia comportamental e da cibernética para o estabelecimento das ciências cognitivas. A rigor, como vimos a partir do texto de Koyré, essa construção iniciou-se já nos primórdios da Idade Moderna.

Contrariamente a esta escolha epistemológica dos ciberneticistas e de vários setores das ciências cognitivas de excluir o conceito de consciência de seu horizonte teórico, a constituição da psicologia cognitiva possibilitou que

reabilite-se [...] a relevância da consciência, nela se recostando uma função diretiva, organizadora e controladora do comportamento [...] A psicologia cognitiva se revela não apenas - como freqüentemente tem sido apresentada - como uma reação ao mecanicismo e ao behaviorismo, mas como uma reação contra o movimento irracionalista que, na verdade, deriva-se, particularmente, de Nietzche. Exprime ainda um movimento de reação no sentido de repropor a consciência como tema central da psicologia e como instância altamente significativa no que concerne ao controle do comportamento (PENNA, 1999, p. 25, 32) (grifo da autora).

Assim, na perspectiva da psicologia cognitiva não se tem a intenção de enraizar a consciência em nenhum "recanto cerebral", como quer a neurobiologia cognitiva, mesmo porque, tal estratégia teórica já foi proposta na psicologia por James no século XIX. O que é necessário para a psicologia cognitiva é encontrar uma metodologia de pesquisa que a instrumentalize a investigar os processos cognitivos, dentre eles a aprendizagem e a linguagem, bem como o fenômeno da consciência, sem as limitações e compromissos que temos visto em outros setores das ciências cognitivas. 
Como a LC rompeu com a perspectiva gerativista ${ }^{25}$ por esta congregar em si todo o pensamento hegemônico das ciências cognitivas, é necessário que ela não se vincule a outros setores das ciências cognitivas que continuam atrelados ao projeto de reificação do ser humano. Parecenos que a LC somente terá todo o seu potencial teórico-metodológico plenamente desenvolvido quando ela conseguir estabelecer uma discussão epistemológica mais firme. Caso contrário ela corre o risco de ter rompido com o pensamento hegemônico chomskyano e, paradoxalmente, atrelar-se a uma outra vertente hegemônica dentro do amplo universo das ciências cognitivas, como, por exemplo, ao conexionismo e mesmo à biologia do conhecer, pelas razões por nós apontadas.

Buscar construir uma aliança entre a LC e a psicologia cognitiva que se afilie à tradição gestaltista é o desafio que pode ter como resultado a ampliação da compreensão dos conceitos de cognição, linguagem, aprendizagem e consciência, uma vez que a psicologia cognitiva mantém em seu campo de investigação o que foi o seu objeto de estudo no início de sua fundação: a consciência. Contudo, a psicologia foi extremamente criticada por investigar tal fenômeno através do método introspectivo, ${ }^{26}$ pois segundo alguns pesquisadores, como os comportamentalistas, esse método não era científico. Desde então, tanto a psicologia quanto a lingüística avançaram muito em suas pesquisas e metodologia, havendo mesmo trocas profícuas entre ambas, como foi o caso da constituição da psicolingüística, em 1954 e da própria LC,

25 Não é objetivo deste texto discutir o trabalho de Chomsky. Sabemos que Chomsky revê continuamente alguns de seus princípios teóricos desde as suas primeiras formulações nos anos de 1950 (cf. NETO, 2004, p. 93-130; SILVA E COSTA, 2004, p. 131-164). Contudo, Chomsky mantém premissas básicas em sua teoria, as quais alojam o seu trabalho, confortavelmente, na perspectiva hegemônica da ciência moderna. Podemos lembrar a sua afirmação de 1996, feita em um seminário proferido em Brasília, de que "é razoável considerar a faculdade da linguagem como um órgão da linguagem” (CHOMSKY, 1998, p. 19). A redução das faculdades humanas ao biológico é uma das premissas mais fortes do que tenho chamado "projeto da ciência moderna".

${ }^{26}$ Atualmente há uma "readmissão da introspecção" como método de pesquisa entre os psicólogos (Cf. SCHULTZ e SCHULTZ, 2005, p. 439). 
que vê na psicologia cognitiva uma referência importante (Cf. LANGACKER, 1987). Assim, resta-nos perguntar sobre a possibilidade de investigar o fenômeno da consciência através de métodos lingüísticos. Acreditamos em uma resposta positiva. Mais ainda, acreditamos que será possível desenvolver uma metodologia de pesquisa que "libere" o fenômeno de um enquadre teórico muito estreito, ou seja, que a teoria, dada a priori, não defina o que deve ser "visto" ou "encontrado" ao final da pesquisa. A certeza que se tem é que, diante de um novo objeto de estudo, é necessário o desenvolvimento de nova metodologia. Neste sentido podemos aprender com a ciência da história, que

precisou adaptar seus métodos de pesquisa às condições extremamente diversas dos períodos e dos aspectos do passado por ela estudados. Os historiadores do Egito faraônico, da filosofia grega, da sociedade feudal, da arte barroca ou da sociedade capitalista não utilizaram os mesmos gêneros de documentos (GLÉNISSON, 1979, p. 143).

Ou seja, "investigar" o ser humano como um ser que possui consciência é diferente de procurar entendê-lo nivelando-o aos animais em um continuum evolutivo biológico, ou reduzi-lo a um autômato.

A ponderação de Penna (2003) de que até 1951, os estudos de psicologia da linguagem raramente se beneficiavam das pesquisas da lingüística, leva-nos a inferir que há muito ainda que se fazer para buscar refinar um trabalho metodológico conjunto da lingüística e da psicologia. Assim, acreditamos que a proposta da LC de buscar desenvolver um método investigativo conjunto com a psicologia cognitiva, como comenta Langacker (1987), pode significar uma nova ampliação para os benefícios que tal associação tem trazido não só para ambas as disciplinas, mas para o campo da ciência em geral.

Teixeira (2003, p. 160-170) estabelece que o que é inovador na metodologia da neurociência cognitiva é "se voltar para o papel do cérebro como substrato biológico da cognição e da consciência [...] a neurociência constitui uma metodologia para uma investigação empírica da natureza da consciência”. Contudo essa nova metodologia voltaria a priorizar o papel da biologia, agora representada pelo cérebro, e comportamento humanos. Este foi o referencial teórico-metodológico da psicologia comportamental que via, inclusive, a linguagem como um comportamento, comportamento verbal (Cf. SKINNER, 1978). Na verdade, então, a neurociência cognitiva continua a sustentar uma das 
bases fundacionais da ciência moderna, a redução do ser humano à sua biologia. O que temos discutido até o momento nos permite perceber que o que tem ocorrido dentro das ciências cognitivas é uma oscilação entre os modelos e metodologias que exploram mais os aspectos lógico-matemáticos, especificamente a partir do cognitivismo em 1956 (Cf. VARELA et alii, 2003, p. 53-72) para compreender a cognição humana, e aqueles que exploram mais os aspectos biológicos, cerebrais, como a neurociência cognitiva e o conexionismo.

Buscar construir uma nova metodologia que abarque a relação linguagem, cognição, consciência e aprendizagem demanda que se repense a própria ontologia constituída na modernidade. É necessário, por exemplo, que se investigue a natureza da consciência, antes de torná-la equivalente aos processos cognitivos. Assim, a construção dessa nova metodologia pode significar a ruptura do paradigma da mensuração, pilar na ciência moderna e ainda fortemente presente na ciência da modernidade tardia. A psicologia comportamental, por exemplo, construiu todo o seu arcabouço teórico-metodológico partindo da premissa de que a mensuração do comportamento humano é suficiente para se estabelecer uma ontologia humana. Dessa maneira, o movimento da LC de buscar se associar à psicologia cognitiva de forma mais consistente torna-se extremamente relevante, pois possibilita que os dois campos teóricos se repensem para viabilizar uma nova metodologia que apreenda o ser humano de uma forma menos reducionista. Essa nova associação pode encontrar formas de abordar a consciência sem que esta seja reduzida ao biológico e nem a cálculos lógicos, o que trará uma grande contribuição para a ciência. Seguramente o fortalecimento dessa aliança terá uma importância crucial para a psicologia cognitiva, pois a corrente hegemônica dessa disciplina também associou suas pesquisas à inteligência artificial e mesmo à neurociência, vendo a cognição como processamento de informação (Cf. TIJUS, 2003; ANDERSON, 2004; STERNBERG, 2000). O estabelecimento dessa nova metodologia poderá trazer, ainda, uma mudança no próprio referencial teórico, isto é, na compreensão dos fenômenos da cognição e consciência humanas, com isto confirmando a tese proposta por Koyré de que 
as grandes revoluções científicas [...] são fundamentalmente revoluções teóricas, cujo resultado não foi a melhoria da conexão entre elas e os "dados da experiência", mas a aquisição de uma nova concepção da realidade profunda subjacente àqueles 'dados” (grifo da autora).

Partindo dessa formulação de Koyré de que é a inovação teórica que amplia a compreensão dos próprios dados que investigamos, pode-se esperar que o desenvolvimento de uma teoria mais refinada, dentro da ciência, para abordar o conceito de consciência pode possibilitar uma alteração na compreensão dos processos cognitivos e, portanto, da linguagem e da aprendizagem.

Contudo, refletir sobre esse desafio, buscando construir uma nova metodologia, seria tema para uma outra discussão, a qual implicaria pensar o projeto da transdisciplinaridade na ciência da modernidade tardia, por exemplo. Neste texto procuramos, apenas, apontar para alguns limites epistemológicos e ontológicos que permeiam as ciências cognitivas, limites que são, na verdade, oriundos da ciência moderna e que foram transportados para as ciências cognitivas, sendo uma das razões para tal transposição o fato de as ciências cognitivas terem se tornado a ciência normal na modernidade tardia.

\section{Referências Bibliográficas}

ABIB, J. Skinner, materialista metafísico? "Never mind, no matter". In: PRADO, B. J. (Org.). Filosofia e comportamento. São Paulo: Editora Brasiliense, 1982. (Coleção Almanaque). p. 92-109.

ANDERSON, J. Psicologia cognitiva e suas implicações experimentais. Rio de Janeiro: LTC , 2004. 307p.

BACHELARD, G. O novo espírito científico. 2. ed. Rio de Janeiro: Tempo Brasileiro, 1985.

BAKHTIN, M. Marxismo e filosofia da linguagem: problemas fundamentais do método sociológico na ciência da linguagem. 3. ed. São Paulo: HUCITEC, 1986. 196p.

BEHE, M. A caixa preta de Darwin: o desafio da bioquímica à teoria da evolução. Rio de Janeiro: Jorge Zahar Editor, 1997. 300p.

BURTT, E. As bases metafísicas da ciência moderna. Brasília: Editora Universidade de Brasília, 1983 (Coleção Pensamento Científico). 268p. 
CALVET DE MAGALHÃES, T. Filosofia analitica - de Wittgenstein à redescoberta da mente. Belo Horizonte, 1997.

CAPRIA, M. (Org.). A construção da imagem científica do mundo. São Leopoldo: Editora Unisinos, 2002. 428p.

CHOMSKY, N. Reflexões sobre a linguagem. São Paulo: Cultrix, 1980. 198p. Linguagem e mente. Brasília: Editora UnB, 1998. 83p.

COLLIER, M. On the compatibility of connectionism and cognitive linguistics. University of California, San Diego, June. 1998. Disponível em: < http:// www.crl.uesd.edu/newsletter.html> Acesso em: 20 jan. 2005.

COSTA, J.; SILVA, M. C. Os anos 1990 na gramática gerativa. In: MUSSALIM, F.; BENTES, A. C. (Org.). Introdução à lingüística-fundamentos epistemológicos. v. 3. São Paulo: Cortez, 2004. p. 131- 164.

DAMÁSIO, A. R. O erro de Descartes: emoção, razão e o cérebro bumano. $8^{a}$ reimpressão. São Paulo: Companhia das Letras, 2001. 330p.

. O mistério da consciência: do corpo e das emoções ao conbecimento de si. $5^{\text {a }}$ reimpressão. São Paulo: Companhia das Letras, 2000. 474p.

. Em busca de Espinosa: prazer e dor na ciência dos sentimentos. $1^{\mathrm{a}}$ reimpressão. São Paulo: Companhia das Letras, 2004. 358p.

DARWIN, C. A origem das espécies e a seleção natural. [s.1.]: Hemus, 2003. 471p.

DUPUY, J. Nas origens das ciências cognitivas. São Paulo: Editora UNESP, 1996. 228p.

FADIMAN, J.; FRAGER, R. Teorias da personalidade. São Paulo: Editora Harper \& Row do Brasil Ltda, 1979. 393p.

FAIRCLOUGH, N. Discurso e mudança social. Brasilia: UNB, 2001. 316p. . Discourse in late modernity. Londres: The University Press, Cambridge, 1999. 154p. Language and power. Inglaterra: Longman Group, 1989. 259p.

FIGUEIREDO, L. Matrizes do pensamento psicológico. Petrópolis: Vozes, 1991. 208p.

FOUREZ, G. A construção das ciências-introdução à filosofia è à ética das ciências. São Paulo: Editora UNESP, 1995. 319p.

FRAWLEY, W. Vygotskye a ciência cognitiva-linguagem e integração das mentes social e computacional. Porto Alegre: ARTMED, 2000. 288p. 
GARDNER, H. A nova ciência da mente. 2. ed. São Paulo: EDUSP, 1996. 454p. GLÉNISSON, J. Iniciação aos estudos históricos. 3. ed. Rio de Janeiro: Difel, 1979. 370p.

HALLIDAY, M.; MARTIN, J. Writing science: literacy and discursive power. London: University of Pittsburgh Press, 1993. 283p.

JANDA, L. Cognitive Linguistics. University of North Carolina, February. 2000. Disponível em: < http://www.indiana.edu/ slavconf/SLING 2K/pospapers/ janda.pdf $>$ Acesso em: 20 jan. 2005.

KOFFKA, K. Princípios de Psicologia da Gestalt.São Paulo: Cultrix, 1975. 703p.

KOYRÉ, A. Estudos de bistória do pensamento científico. 2. ed. São Paulo: Editora Forense Universitária, 1991. 388p.

KUHN, T. A estrutura das revoluções científicas. 6. ed. São Paulo: Editora Perspectiva, 2001. 257p.

LACLAU, E.; MOUFFE, C. Hegemony \& socialist strategy-towards a radical democratic politics. Londres: Verso, 1985. 197p.

LANGACKER, R. Foundations of cognitive grammar - theoreticalprerequisites. California: Stanford University Press, 1987. 516p.

MARX, M.; HILLIX, W. Sistemas e teorias em psicologia. 10. ed. São Paulo: Cultrix, 1997. 755p.

MELO, L. A psicolingüística: objeto, campo e método. In: (Org.)

Tópicos de psicolingüística aplicada. 2. ed. São Paulo: Humanitas, 1999. p. 13-25.

NETO, J. B. O empreendimento gerativo. In: MUSSALIM, F.; BENTES, A C (Org.). Introdução à lingüistica - fundamentos epistemológicos. v. 3. São Paulo: Cortez, 2004. p. 93-130.

OLSON, D. A escrita e a mente. In: WERTSCH, J. et alii. Estudos socioculturais da mente. Porto alegre: ARTMED, 1998. p. 89-111.

PENNA, A. Introdução à história da psicologia contemporânea. 2. ed. Rio de Janeiro: Zahar Editores, 1980. . Repensando a psicologia. Rio de Janeiro: Imago, 1997. 297p. Introdução à psicologia cognitiva. $2^{\mathrm{a}}$ ed. ampl. São Paulo: EPU, 1999. 185p.

. Introdução à psicologia fenomenológica. Rio de Janeiro: Imago, 2001 (Coleção Introdução à psicologia). 121p. 
PENNA, A. Introdução à psicologia da linguagem e do pensamento. Rio de janeiro: Imago, 2003 (Coleção Introdução à psicologia). 141p.

PERFEITO, A.M. Discurso da escrita: da teoria à prática. In: MELO, L. (Org). Tópicos de psicolingüística aplicada. 2. ed. São Paulo: Humanitas/FFLCH/ USP, 1999. p. 75-94.

PESSOTTI, I. Movimento muscular e comportamento: notas históricas. In: PRADO, B. J. (Org.). Filosofia e comportamento. São Paulo: Editora Brasiliense, 1982. (Coleção Almanaque). p. 11-32.

ROSE, J. Consciência e propósito no behaviorismo radical. In: PRADO, B. J. (Org.). Filosofia e comportamento. São Paulo: Editora Brasiliense, 1982. (Coleção Almanaque). p. 67-91.

ROSE, M. O espectro de Darwin: a teoria da evolução e suas implicações no mundo moderno. Rio de Janeiro: Jorge Zahar Editor, 2000. 264p.

SAPIR, E. Lingüística como ciência - ensaios. Rio de Janeiro: Livraria Acadêmica, 1969. 205 p.

SCHOENFELD, A. Looking toward the 21st Century: challenges of educational theory and practice, California, Jully. 1999. Disponível em: <http://www.gse.berkeley.edu/faculty/aschoenfeld/AREA_final.pdf > Acesso em: jan. 2005.

SCHULTZ, D.; SCHUTZ, S. História da psicologia moderna. 16. ed. São Paulo: Cultrix, 1992. 440p.

SCHULTZ, D.; SCHUTZ, S. História da psicologia moderna-tradução da oitava edição norte-americana. São Paulo: Pioneira Thomson Learning Ltda, 2005. 484p.

SEARLE, J. R. O mistério da consciência. São Paulo: Paz e Terra, 1998. 239p. SERMONTI, G. A conceituação de vida: de Aristóteles a Darwin e à atualidade. In: CAPRIA, M. (Org.). A construção da imagem científica do mundo - as mutações nas concepções do homem e do cosmos desde o descobrimento da América até a mecânica quântica. São Leopoldo: Editora Unisinos, 2002. 428p.

SKINNER, B. Questões recentes na análise do comportamento. Campinas: Papirus, 1991. 193p.

. Ciência e comportamento bumano. 6a ed. São Paulo: Martins Fontes, 1985. 420p.

. O comportamento verbal. São Paulo: Cultrix, 1978. 256p. 
SKINNER, B. Sobre o behaviorismo. São Paulo: Editora Pensamento-Cultrix, 1979. 216p.

. A Psicologia pode ser uma ciência da mente? 1990. 7p. Disponível em: <http://www.suigeneris.pro.br/edvariedade_psicociecia.htm> Acesso em: 20 jan. 2005.

SINHA, C. "Cognitive linguistics, psychology and cognitive science". Draft chapter for D. Geeraerts and H. Cuyckens (Ed.). Handbook of Cognitive Linguistics. Oxford, Oxford University Press, 2001. 35p.

STERNBERG, R. Psicologia cognitiva. Porto Alegre: ARTMED, 2000. 494p.

STRATHERN, P. Turing e o computador em 90 minutos. Rio de Janeiro: Jorge Zahar Ed., 2000. 89p.

TEIXEIRA, J. Mente, cérebro e cognição. Petrópolis: Vozes, 2003. 197p. . Mentes e máquinas - uma introdução à ciência cognitiva. Porto Alegre: ARTMED, 1998. 179p.

TIJUS, C. Introdução à psicologia cognitiva. Lisboa: CLIMEPSI EDITORES, 2003. 222p.

TOMASELLO, M. Origens culturais da aquisição do conbecimento bumano. São Paulo: Martins Fontes, 2003. 342p.

TREVISAN, P. Empirismo e psicologia. In: PRADO, B. J. (Org.) Filosofia e comportamento. São Paulo: Editora Brasiliense, 1982. (Coleção Almanaque). p. 32-64.

VARELA, F. et alii. A mente incorporada-ciências cognitivas e experiência bumana. Porto Alegre: ARTMED, 2003. 293p.

VIGOTSKI, L. Pensamento e linguagem. São Paulo: Martins Fontes, 2003. $194 \mathrm{p}$.

WEEDWOOD, B. História concisa da lingüística. São Paulo: Parábola Editorial, 2002. 165p.

WERTSCH, J. et alii. Estudos socioculturais da mente. Porto alegre: ARTMED, 1998. 214p.

WIGNER, E. Remarks on the mind-body question. In: GOOD, I.J. The scientist speculates: An anthology of partly baked ideas. Londres: Heinemann, 1962 apud TEIXEIRA, J. Mente, cérebro e cognição. Petrópolis: Vozes, 2003. 197p. 